ISSN Cetak : :2087-0434

E-ISSN : :2599-0810

\title{
PERSEPSI KONSUMEN TERHADAP KUALITAS PRODUK WEDDING PHOTOGRAPHY KLANGENAN ART
}

\author{
Gusti Adi Pranoto ${ }^{1)}$ \\ Fakultas Ekonomi dan Bisnis, Universitas Muhammadiyah Pringsewu \\ Email: gustiadipranoto@umpri.ac.id
}

\begin{abstract}
Abstrak
KLART sebuah perusahaan di bidang jasa Wedding Photography yang sudah berdiri sejak tahun 2019. Meningkatnya persaingan Wedding Photography di Pringsewu, membuat KLART harus menciptakan kualitas foto yang baik sehingga menciptakan persepsi yang positif dari konsumen. Persepsi konsumen dalam melihat hasil foto KLART menjadi penting untuk di ketahui agar KLART dapat mengevaluasi hasil dari kualitas produk Wedding Photography. Jenis penelitian menggunakan metode penelitian kuantitatif dengan menggunakan teknik pengumpulan data berupa wawancara dengan intstrumen Kuisioner. Peneliti menggunakan skala likert, yaitu skala ini digunakan untuk mengukur sikap, pendapat dan persepsi seseorang atau kelompok orang tentang fenomena atau gejala sosial yang terjadi. Penelitian ini dilakukan untuk mengetahui bagaimana persepsi konsumen terhadap kualitas produk Wedding Photography KLANGENAN ART. Hasil dari penelitian ini menunjukkan adanya persepsi yang positif dari pelanggan terhadap kualitas Wedding Photography KLANGENAN ART.
\end{abstract}

Kata Kunci: Kualitas Produk, Wedding Photo, Photography, Persepsi

\section{PENDAHULUAN}

Wedding Photography adalah salah satu cabang bisnis Photography yang banyak di butuhkan oleh masyarakat dalam melaksanakan pesta pernikahan. Pringsewu adalah kota yang di dalamnya terdapat banyak penggiat jasa Wedding Photography, salah satunya adalah KLANGENAN ART atau lebih di kenal KLART. KLART sebuah perusahaan di bidang jasa Wedding Photography yang sudah berdiri sejak tahun 2019. Konsumen KLART sendiri sudah tersebar di beberapa kota baik di Pringsewu maupun Bandar Lampung. Meningkatnya persaingan Wedding Photography di Pringsewu, membuat KLART harus menciptakan kualitas foto yang baik sehingga menciptakan persepsi yang positif dari konsumen. 
ISSN Cetak : :2087-0434

E-ISSN : :2599-0810

Kualitas Produk dalam Olayeni, A., Ogbo, A., Okwo, H., Chukwu, B., Ifediora, C., \& Ezenwakwelu, C. (2021) adalah fitur intrinsik dari produk yang membuatnya lebih unggul atau lebih disukai daripada produk pengganti. Dimensi kualitas produk dalam Thahir, A. P., Rohayati, Y., \& Hadining, A. F. (2015) adalah: 1) Performance (kinerja), berhubungan dengan karakteristik operasi dasar dari sebuah produk. 2) Durability (daya tahan), yang berarti berapa lama atau umur produk yang bersangkutan bertahan sebelum produk tersebut harus diganti. Semakin besar frekuensi pemakaian konsumen terhadap produk maka semakin besar pula daya produk. 3) Conformance to specifications (kesesuaian dengan spesifikasi), yaitu sejauh mana karakteristik operasi dasar dari sebuah produk memenuhi spesifikasi tertentu dari konsumen atau tidak ditemukannya cacat pada produk. 4) Features (fitur), adalah karakteristik produk yang dirancang untuk menyempurnakan fungsi produk atau menambah ketertarikan konsumen terhadap produk. 5) Aesthetics (estetika), berhubungan dengan bagaimana penampilan produk. 6) Perceived quality (kesan kualitas), sering dibilang merupakan hasil dari penggunaan pengukuran yang dilakukan secara tidak langsung karena terdapat kemungkinan bahwa konsumen tidak mengerti atau kekurangan informasi atas produk yang bersangkutan. 7) Serviceability, meliputi kecepatan dan kemudahan untuk direparasi, serta kompetensi dan keramahtamahan staf layanan. Tidak Semua dimensi kualitas di atas dapat digunakan dalam penelitian ini. Dibutuhkan penyesuaian dimensi kualitas terhadap objek penelitian yang merupakan produk Wedding Photography. Dimensi kualitas yang digunakan dalam penelitian ini adalah 1) Features, 2) Perceived quality, 3) Serviceability.

Konsumen membuat kesimpulan tentang banyak atribut produk, termasuk atribut fungsional seperti kualitas produk, melalui tampilan visual produk (Schnurr, B., Brunner-Sperdin, A., \& Stokburger-Sauer, N. E. (2017). Persepsi konsumen dalam melihat hasil foto KLART menjadi penting untuk di ketahui agar KLART dapat mengevaluasi hasil dari kualitas produk Wedding Photography. Sebagaimana Persepsi dalam Tran, H. N., \& Nguyen, M. D. (2020) adalah proses memilih, mengatur, dan menginterpretasikan sensasi menjadi satu kesatuan yang bermakna. 
ISSN Cetak : :2087-0434

E-ISSN : $\quad$ 2599-0810

\section{METODE PENELITIAN}

Jenis dalam penelitian ini menggunakan metode penelitian kuantitatif dengan menggunakan teknik pengumpulan data berupa wawancara dengan intstrumen Kuisioner. Dalam menyebarkan kuesioner penelitian, peneliti menggunakan Google Form untuk disebarkan dengan mengirimkan link kuesioner secara langsung ini kepada responden. Responden pada penelitian ini adalah konsumen yang telah memakai jasa Wedding Photography KLANGENAN ART pada tahun 2021 sebanyak 16 Orang. Peneliti menggunakan skala likert, yaitu skala ini digunakan untuk mengukur sikap, pendapat dan persepsi seseorang atau kelompok orang tentang fenomena atau gejala sosial yang terjadi (Iskandar, 2009). Dengan poin penilaian sebagai berikut: Sangat Setuju (SS) : diberi skor 5, Setuju (S) : diberi skor 4, Netral (N) : diberi skor 3, Tidak Setuju (TS) : diberi skor 2, Sangat Tidak Setuju (STS) : diberi skor 1

\section{HASIL DAN PEMBAHASAN}

Setelah penelitian dilakukan, peneliti mendapatkan penilaian jawaban responden pada tabel 1

Tabel 1

Tanggapan Responden

\begin{tabular}{|c|c|c|c|c|c|c|c|}
\hline \multirow{2}{*}{ No } & \multirow{2}{*}{ Pernyataan } & \multicolumn{5}{|c|}{ Penilaian } & \multirow{2}{*}{ Rata-Rata } \\
\hline & & STS & TS & $\mathbf{N}$ & $\mathbf{S}$ & SS & \\
\hline \multicolumn{7}{|c|}{ Features (fitur) } & \\
\hline 1 & $\begin{array}{l}\text { Hasil Foto Wedding Photography } \\
\text { KLANGENAN ART mempunyai ciri khas }\end{array}$ & $\mathbf{0}$ & $\mathbf{0}$ & 3 & 28 & 40 & 4,44 \\
\hline 2 & $\begin{array}{l}\text { Hasil cetakan foto Wedding Photography } \\
\text { KLANGENAN ART mempunyai ciri khas }\end{array}$ & $\mathbf{0}$ & $\mathbf{0}$ & $\mathbf{0}$ & 36 & 25 & 3,81 \\
\hline \multicolumn{7}{|c|}{ Aesthetics (Estetika) } & \\
\hline 3 & $\begin{array}{l}\text { Foto yang di hasilkan memiliki } \\
\text { estetika/keindahan }\end{array}$ & $\mathbf{0}$ & $\mathbf{0}$ & 3 & 24 & 45 & 4,50 \\
\hline 4 & Susunan album foto terkonsep & $\mathbf{0}$ & $\mathbf{0}$ & $\mathbf{0}$ & 40 & 30 & 4,38 \\
\hline \multicolumn{7}{|c|}{ Perceived Quality (Kesan Kualitas) } & \\
\hline 5 & Hasil cetakan foto berkualitas & $\mathbf{0}$ & $\mathbf{0}$ & $\mathbf{0}$ & 44 & 25 & 4,31 \\
\hline
\end{tabular}


$\begin{array}{ll}\text { ISSN Cetak } & : 2087-0434 \\ \text { E-ISSN } & : 2599-0810\end{array}$

\begin{tabular}{|c|c|c|c|c|c|c|c|}
\hline 6 & Kualitas foto profesional & $\mathbf{0}$ & $\mathbf{0}$ & 3 & 24 & 45 & 4,50 \\
\hline \multicolumn{8}{|c|}{ Serviceability } \\
\hline 7 & Foto terkonsep dengan baik & $\mathbf{0}$ & $\mathbf{0}$ & 3 & 24 & 45 & 4,50 \\
\hline 8 & Pelayanan fotografer ramah & $\mathbf{0}$ & $\mathbf{0}$ & $\mathbf{0}$ & 8 & 70 & 4,88 \\
\hline 9 & $\begin{array}{l}\text { Fotografer dapat mengarahkan pose dengan } \\
\text { baik }\end{array}$ & $\mathbf{0}$ & $\mathbf{0}$ & 3 & 16 & 55 & 4,63 \\
\hline \multicolumn{8}{|c|}{ Aesthetics (Estetika) } \\
\hline 10 & $\begin{array}{l}\text { Foto yang di hasilkan memiliki } \\
\text { estetika/keindahan }\end{array}$ & $\mathbf{0}$ & $\mathbf{0}$ & $\mathbf{0}$ & 32 & 40 & 4,50 \\
\hline
\end{tabular}

Sumber: data Kuisoner yang telah diolah 2021

Berdasarkan table 1 diatas, terlihat pernyataan nomor 1 sampai dengan 10 nilai rata-rata di atas 4, 20 dengan arti nilai interpretasi sangat baik, kecuali soal nomor dua dimana memiliki rata-rata 3, 81. Namum hal tersebut masih dalam interpretasi baik. Sebagaimana Interpretasi nilai rata-rata jawaban responden dalam (Pranoto et al., 2020) terdapat pada Tabel 2.

Table 2

Interpretasi Nilai Rata-Rata Tanggapan Responden

\begin{tabular}{cc|}
\hline Nilai & Keterangan \\
\hline $4,21-5,00$ & Sangat Tinggi \\
$3,41-4,20$ & Baik \\
$2,61-3,40$ & Cukup Tinggi \\
$1,81-2,60$ & Rendah \\
$1,00-1,80$ & Sangat Rendah \\
\hline
\end{tabular}

Sumber: (Pranoto et al., 2020)

Berdasarkan table 1 dan 2 dari setiap pertanyaan memiliki interpretasi nilai rata-rata sangat tinggi. Terlebih pada pertanyaan nomor 8 tentang "pelayanan fotografer yang ramah" mendapatkan nilai rata-rata 4, 88. Hal ini menandakan responden mendapatkan pelayanan yang ramah dari fotografer Klangenan Art dan menilai kualitas dari Wedding Photography KLANGENAN ART baik, Sehingga adanya presepsi yang positif konsumen terhadap kualitas produk Wedding Photography KLANGENAN ART. 
ISSN Cetak : :2087-0434

E-ISSN : $: 2599-0810$

\section{KESIMPULAN}

Hasil penelitian menunjukkan bahwa adanya persepsi yang positif terhadap kualitas Wedding Photography KLANGENAN ART. Penelitian ini memiliki keterbatasan, sehingga saran yang dapat diberikan agar penelitian selanjutnya dapat menambah variable, seperti kepuasan, dan word of mouth, agar mengetahui tingkat kepuasan dan effect word of mouth konsumen Wedding Photography KLANGENAN ART sehingga diharapkan dapat menajadi penelitian yang lebih baik dimasa yang akan datang.

\section{DAFTAR REFERENSI}

Iskandar. (2009). Metodologi Penelitian Kualitatif. Jakarta: Gaung Persada Press.

Olayeni, A., Ogbo, A., Okwo, H., Chukwu, B., Ifediora, C., \& Ezenwakwelu, C. (2021). Green strategy effect on financial and environmental performance: a mediation analysis of product quality. Sustainability (Switzerland), 13(4), 117.

Pranoto, G. A., Bangsawan, S., \& Pandjaitan, D. H. R. (2020, July). Influence of quality service and satisfaction imagery higher education on Word of Mouth (WOM). In The Future Opportunities and Challenges of Business in Digital Era 4.0: Proceedings of the 2nd International Conference on Economics, Business and Entrepreneurship (ICEBE 2019), November 1, 2019, Bandar Lampung, Indonesia (p. 128). Routledge.

Schnurr, B., Brunner-Sperdin, A., \& Stokburger-Sauer, N. E. (2017). The effect of context attractiveness on product attractiveness and product quality: the moderating role of product familiarity. Marketing Letters, 28(2), 241-253.

Thahir, A. P., Rohayati, Y., \& Hadining, A. F. (2015). Pengembangan Kualitas Produk Dodol Rumput Laut Ukm Aulia Sari Menggunakan Integrasi Dimensi Kualitas Produk Dan Model Kano. Jurnal Rekayasa Sistem \& Industri (JRSI), 2(04), 33.

Tran, H. N., \& Nguyen, M. D. (2020). Customer perception toward electronic commerce systems in Vietnam. Management Science Letters, 10(12), 28612868. 